\title{
Penatalaksanaan Perawatan Saluran Akar pada Fraktur Gigi 21 disertai Perforasi
}

Zieta Sakinah Emdi ${ }^{1}$, Reni Nofika ${ }^{1}$

Korespondensi : Reni Nofika; [reninofika@gmail.com] Telp: [081363475034]

\begin{abstract}
Root canal treatment aims to maintain the condition of the teeth in order to keep them functioning. In practice, the treatment procedure does not always run smoothly, the operator can face undesirable conditions that can affect the prognosis of treatment. A common procedural error during root canal treatment is a lateral root perforation which must be treated immediately to avoid further damage. The success of the perforation treatment is determined by the materials used. One of the bicompatible materials to seal lateral perforations using MTA (mineral trioxide aggregate). Successful root canal treatment affects treatment outcomes, so proper restoration is required to reduce the risk of marginal leakage. The choice of final restoration in post-root canal treatment depends on the amount of remaining tooth structure, horizontal pressure and chewing load. For post-root canal treatment anterior teeth with intact marginal edges, direct restoration can be performed using composite resin
\end{abstract}

Keywords: lateral perforation; MTA; root canal

Affiliasi penulis: ${ }^{1}$ Fakultas Kedokteran Gigi, Universitas Andalas, Padang, Sumatera Barat, Indonesia.

\section{PENDAHULUAN}

Perawatan saluran akar bertujuan mempertahankan gigi agar tetap dapat berfungsi. Tahap perawatan saluran akar antara lain: preparasi saluran akar yang meliputi pembersihan dan pembentukan (biomekanis), disinfeksi, dan pengisian saluran akar. ${ }^{2}$ perawatan saluran akar tidak selalu berjalan lancar, operator dapat menghadapi keadaan yang tidak diinginkan sehingga dapat mempengaruhi prognosis perawatan. Kesalahan prosedur yang sering terjadi selama perawatan saluran akar adalah perforasi akar lateral yang harus segera dirawat untuk menghindari kerusakan lebih lanjut. Perforasi lateral ditandai dengan nyeri spontan, perdarahan spontan, nyeri selama irigasi dengan naocl. Keberhasilan perawatan perforasi ditentukan oleh bahan material yang digunakan. Salah satu bahan material yang bikompatibel untuk menutup perforasi lateral menggunakan mta (mineral trioxide aggregat). ${ }^{3,4}$

Prinsip dasar desain restorasi pada gigi pasca perawatan saluran akar yaitu desain harus mempertahankan struktur gigi yang tersisa dengan meminimalkan penghilangan dentin, memiliki retensi yang baik yang dapat diperoleh dengan struktur dentin yang tersisa arah vertikal atau inti maupun dengan tambahan penggunaan pasak, serta dengan melindungi struktur jaringan gigi yang tersisa. Pada kasus ini akan melaporkan penatalaksanaan perawatan saluran akar dengan perforasi lateral pada gigi 21 dengan mta dan restorasi direct disertai prefabricated fiber reinforced post. 
ANdalas dental journal

Fakultas Kedokteran Gigi Universitas Andalas

Jalan Perintis Kemerdekaan No. 77 Padang, Sumatera Barat

Web: adj.fkg.unand.ac.id Email: adj@dent.unand.ac.id

\section{KASUS}

Pasien Laki-laki 18 tahun datang ke RSGM FKG Unand dengan keluhan gigi depan berubah warna dirasakan lebih kurang 3 tahun yang lalu, riwayat avulsi. Saat ini, gigi yang patah tidak terasa sakit dan gusi disekitar gigi yang patah tidak pernah sakit ataupun bengkak. Gigi yang patah belum pernah diobati ataupun dirawat hingga saat ini. Pada pemeriksaan klinis ditemukan gigi 21 fraktur pada bagian insisal, belum melibatkan pulpa disertai dengan perubahan warna pada $1 / 2$ mahkota. Tes palpasi tidak menunjukkan kelainan, EPT (60) negatif, mobility grade 1 dan saat perkusi terasa sakit.
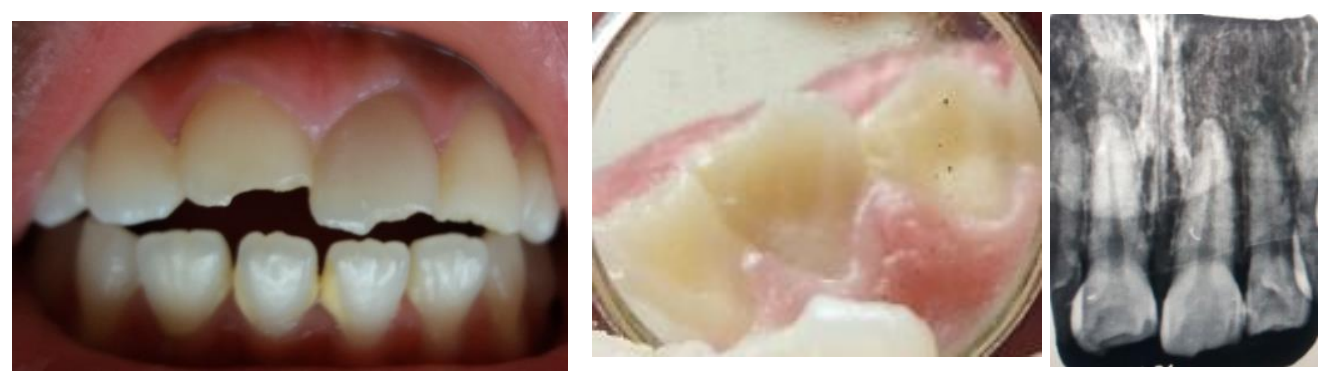

Gambar 1. Gambaran klinis dan radiografi gigi 21 sebelum perawatan

Pada pemeriksaan rontgen periapikal gigi 21 yang menunjukkan kehilangan struktur mahkota di bagian insisal dan belum melibatkan kamar pulpa, memiliki saluran akar tunggal, resorpsi interna pada 1/3 apikal, terlihat lamina dura yang kontinuitasnya terputus dan sudah mulai menghilang disertai pelebaran ligamen periodontal pada daerah periapikal (Gambar 1). Berdasarkan anamnesa, pemeriksaan objektif, pemeriksaan subjektif dan penunjang yang telah dilakukan, ditegakkan diagnosis pada kasus ini adalah gigi 21 nekrosis pulpa disertai periodontitis apikalis kronis. Rencana perawatan akan dilakukan perawatan saluran akar gigi 21 dengan prognosis kasus baik .

Prosedur pertama yang dilakukan adalah preparasi akses dari palatal dengan diamond round bur. Buang atap kamar pulpa mengggunakan safe-end bur dan irigasi dengan NaOCL 2,5\%. Lakukan preparasi saluran akar dengan teknik step back serta tentukan IAF 20 dan MAF 35 dengan panjang kerja 23,5 mm. Kemudian irigasi dengan $\mathrm{NaOCl} 2,5 \%$ dan aquades secara bergantian setiap pergatian file dan lanjutkan dengan preparasi badan saluran akar. Lakukan irigasi dan keringkan saluran akar dengan menggunakan paper point, kemudian aplikasi $\mathrm{Ca}(\mathrm{OH})_{2}$ dan tutup dengan tambalan sementara. Rotasi obat dilakukan 3 kali kunjungan hingga tidak ada keluhan dan pemerikssaan klinis menunjukan respon perbaikan. Lakukan trial dengan gutta percha susuai ukuran MAC, pastikan telah terisi hingga ujung apikal.

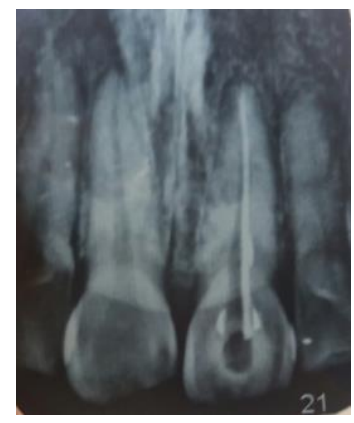

Gambar 2. Hasil trial hingga ujung apikal 
ANDalas deNtal jOURNAL

Fakultas Kedokteran Gigi Universitas Andalas

Jalan Perintis Kemerdekaan No. 77 Padang, Sumatera Barat

Web: adj.fkg.unand.ac.id Email: adj@dent.unand.ac.id
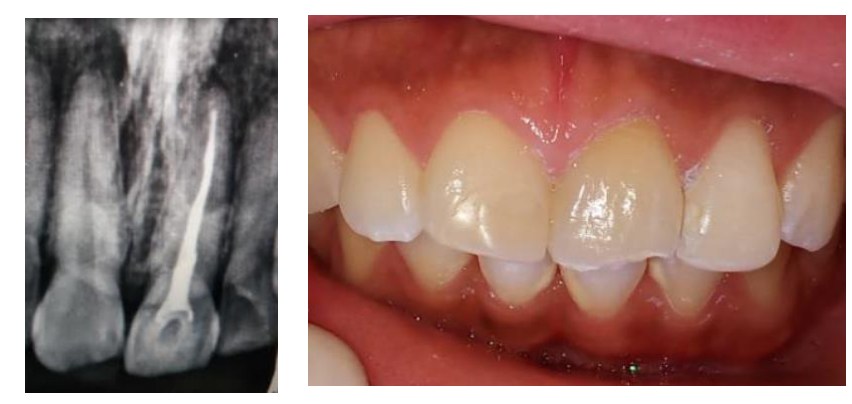

Gambar 3. Radiografi pasca obturasi dan gambaran klinis paska restorasi 1 bulan

Obturasi dilakukan dengan teknik kondensasi lateral. Tutup dengan GIC lining dan tumpatan sementara, lalu menyesuaikan panjang gutta percha untuk persiapan pembuatan pasak. Panjang post sebanding dengan panjang mahkota atau 2/3 panjang akar. Bongkar tambalan sementara, buang semen GIC dengan diamond round bur. Buat akses untuk pengambilan gutta percha menggunakan gates gliden drill. Namun saat penggunaan GGD, terjadi bleeding di mesial dan dilakukan deep dengan cotton pellet, tutup dengan cotton pellet dan tambalan sementara. Dari hasil radiografi terlihat peforasi lateral dimesial $1 / 3$ servikal.

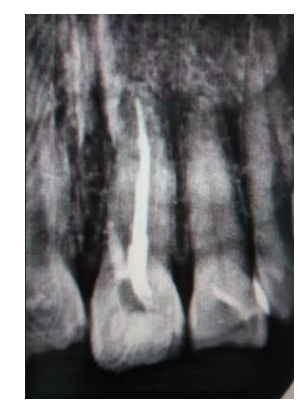

Gambar 4. Kondisi setelah pengaplikasian MTA.

Langkah berikutnya yaitu pengaplikasian MTA (Mineral Trioxide Aggregate). Tes perkusi ngilu, tes tekan, palpasi dan mobility tidak ada kelainan. Bongkar tambalan sementara dan cotton pellet, telah terlihat adanya coating blood. Ukur panjang kerja daerah perforasi menggunakan spreader ukuran kecil. Irigasi daerah perfor menggunakan larutan $\mathrm{NaCL}$ dan biarkan dalan keadaan basah. Aduk MTA sesui petunjuk pabrik, aplikasikan menggunakan spreader sesuai panjang kerja. Padatkan MTA menggunakan microbrush. Tutup dengan cotton pellet steril dan tambalan sementara. Lakukan foto rontgen. Dari hasil radiografi terlihat radiopak pada daerah peforasi lateral dimesial.

Lakukan kontrol pasca aplikasi MTA. Tes perkusi, tes tekan, palpasi dan mobility tidak ada kelainan. Bongkar tambalan sementara dan cotton pellet, bersihkan GIC yang masih tersisa dengan scaller. Buat akses untuk mengeluarkan gutta percha dengan gates glidden drill. Keluarkan gutta percha dengan peeso reamer yang lebih kecil hingga ukuran yang sesuai dengan hasil tracing saluran akar. Saluran akar dibersihkan dengan aquadest dan keringkan dengan paper point steril. Gutta percha yang tersisa sekitar 4 mm di apikal. Tutup dengan cotton pellet steril dan tambalan sementara. Lakukan foto rontgen

Tahapan berikutnya dilanjutkan dengan try in post dan sementasi serta restorasi direct komposit. Lalu pasien datan untuk kontrol paasca restorasi akhir. Pasien tidak memiliki keluhan dan adaptasi tambalan 
bagus, tidak ada traumatic occlusion, tidak ada plak disekitar gigi, keadaan jaringan lunak baik dan $\mathrm{OH}$ pasien juga baik

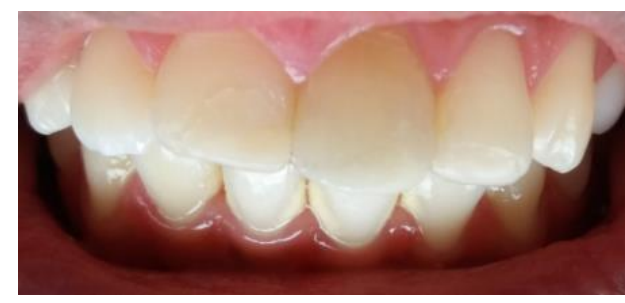

Gambar 5. Gambaran klinis pasca restorasi direct komposit 1 bulan.

\section{DISKUSI}

Perawatan saluran akar pada kasus ini menggunakan medikamen kalsium hidroksida yang dapat meningkatkan terjadinya mineralisasi untuk penyembuhan pulpa terbuka, memiliki kemampuan untuk mempercepat penyembuhan kelainan periapikal, dapat menetralisir aktifitas enzim osteoklast dan proses resorpsi dapat dihentikan.

Teknik preparasi pada kasus ini menggunakan teknik step back dengan teknik obturasi yang menggunakan teknik kondensasi lateral dan teknik single cone. Selanjutnya dilakukan evaluasi perawatan setelah dua minggu pasca pengisian saluran akar yang menunjukkan tidak terdapat kelainan, rasa nyeri, serta tidak sensitif terhadap tes perkusi dan palpasi.

Pada saat pengurangan gutta percha untuk akses post dengan menggunakan gates glidden drill, terjadi perdarahan spontan disertai nyeri. Dari hasil radiographi diketahui perforasi lateral dimesial. Hal ini terjadi karena kesalahan akses. Perforasi iatrogenik dapat terjadi saat akses kavitas, instrumentasi saluran akar, preparasi untuk post ataupun perluasan resorbsi internal akar. Hal ini dapat menyebabkan kerusakan ligamen periodontal dan menginduksi resorpsi tulang alveolar. ${ }^{11}$

Perforasi dapat dirawat melalui akses kavitas, prognosis tergantung dari eliminasi dan pencegahan infeksi di daerah perforasi serta pemilihan bahan. Untuk mendukung penutupan yang baik maka bahan pilihan untuk perbaikan perforasi saluran akar harus biokompatibel, tidak toksik, tidak larut dengan cairan jaringan, tidak resorpsi, radiopak, bakteriostatik dan memiliki kemampuan untuk memicu regenerasi jaringan periradikuler. Pada kasus ini, penanganan perforasi lateral dengan aplikasi MTA (mineral trioxide aggregate). ${ }^{12}$

Salah satu bahan biokompatibel adalah MTA (mineral trioxide aggregate) yang dapat membuat barrier jaringan keras dengan cepat setelah prosedur disinfeksi saluran akar. Material ini memiliki biokompatibilitas yang bagus dan kemampuan penutupan yang baik, serta memiliki $\mathrm{pH}$ yang tinggi yang memberikan sifat antimikroba. Ketika berkontak dengan jaringan periradikular, MTA mempunyai kemampuan menginduksi sementum. MTA menstimulasi produksi interleukim dan sitokin, sehingga menghasilkan pembentukan jaringan keras.. Aplikasi MTA menggunakan spreader ukuran kecil sesuai panjang kerja dan padatkan dengan microbrush lembab. ${ }^{11,12}$ Lakukan evaluasi selama 4 minggu, jika tidak ada keluhan dan tidak ada respon saat pemeriksaan objektif, tahap perawatan dapat dilanjutkan.

Pemilihan restorasi akhir pada gigi pasca perawatan saluran akar tergantung dari banyaknya struktur gigi yang tersisa, tekanan horizontal dan beban pengunyahan. Penggunaan FRC dipiih kareena memiliki beberapa keutungan: modulus elastisitasnya yang hampir sama dengan dentin, berkisar $20 \mathrm{GPa}$ 
ANDALAS DENTAL JOURNAL

Fakultas Kedokteran Gigi Universitas Andalas

Jalan Perintis Kemerdekaan No. 77 Padang, Sumatera Barat

Web: adj.fkg.unand.ac.id Email: adj@dent.unand.ac.id

dibandingkan dengan pasak logam, core dan mahkota, memiliki flexural strength yang lebih baik dari bahan lain, atraumatik, sangat retentif, resistensinya terhadap fraktur yang lebih baik dan resistance fatigue yang lebih baik dibandingkan pasak stainless steel, titanium dan porselin, radiopak memiliki konduktivitas dan light transmission yang dapat mempercepat proses bonding

Pada gigi anterior pasca perawatan saluran akar dengan tepi marginal yang utuh maka dapat dilakukan restorasi direct dengan menggunakan resin komposit. ${ }^{6}$ Pertimbangan pemilihan resin komposit sebagai restorasi akhir pada gigi 21 karena jaringan keras gigi yang tersisa masih cukup banyak dan waktu kunjung pasien yang sangat terbatas. Pada waktu evaluasi menunjukkan keadaan gigi 21 setelah PSA dalam keadaan baik, tidak terdapat lesi periapikal dan secara klinis dapat digunakan dengan baik serta tidak terdapat keluhan dari pasien

\section{SIMPULAN}

Laporan kasus ini membahas perawatan saluran akar dengan diagnosis pulpitis irreversible simptomatik disertai periodontitis apikalis simptomatik pada gigi 21 dengan menggunakan teknik step back. Medicamen intracanal yang digunakan adalah kalsium hidroksida. Melakukan tahapan perawatan saluran akar, dipastikan melakukan dengan sangat hati-hati untuk menghindari terjadinya perforasi iatrogenik. Perforasi lateral dapat dirawat dengan mengaplikasikan MTA. Penggunaan post fiber dan restorasi direk komposit dapat digunakan karena adanya sisa jaringan keras yang cukup dan dengan penggunaan fiber reinforced composite pada kasus ini dapat menambah kekuatan pasca perawatan saluran akar.

\section{KEPUSTAKAAN}

1. Dewi SM., Tunjung Nugraheni. Restorasi Resin Komposit Dengan Pasak Fiber Reinforced Composite Untuk Perbaikan Gigi Insisivus Sentralis Pasca Trauma. Maj Ked Gigi, Juni, 2011; 18(1): 92-97.

2. Lundeen T, F, Roberson TM., Cariology: The lesion, etiology, prevention and control. Dalam studervant. (ed): The art and science operative dentistry. $3^{\text {rd }}$ ed. St louis: Mosby 1995, pp. 60-128.

3. Pace R., et al., Apical Plug Technique Using Mineral Trioxide Aggregate: Result from A Case Series. International Endodontic Journal 2007; 40: 478-484.

4. Muryani A, Opik TH., Rehabilitasi Intra-Radicular Dan Estetika Sesudah Apeksifikasi Dengan Mineral Trioxide Agregat. JMKG 2013; 2(1): 25-35.

5. Besse, T. A., Jn, Juni, Restorasi Pada Gigi Anterior Setelah Perawatan Endodontic. Dentofasial, 2012, 11.3: 187-91.

6. Wijayanti N., Pasak Fiber Reinforced Composite sebagai Penguat Restorasi Resin Komposit Kelas IV pada Gigi Insisivus Lateralis Kanan Maksila Nekrosis Pulpa Disertai Lesi Periapikal (Laporan Kasus). IDJ, 2014; 3(1): 64-70.

7. Masdy W., Nugroho JK., Pasak fiber reinforced komposit. PPDGS Konservasi Gigi Fakultas Kedokteran Gigi Universitas Hasanuddin.

8. Tanumihardja M., Larutan irigasi saluran akar. Dentofasial. 2010; 9(2): 108-115.

9. Nurliza, Cut, et al., Prinsip-Prinsip Dasar Preparasi Saluran Akar Secara Khemomekanis. Dentika Dental Journal, 2014; 18.2: 177-184. 
10. Young G.R., Parashos P., Messer HH., The principles of techniques for cleaning root canals. Aust Dent. 2007; 52 (1 Suppl): S52-S63.

11. Adiga S., Ida A., Subhash A., Nonsurgical Approach for Strip Perforation Repair Using Mineral Trioxide Aggregate. J Conserv Dent, 2010; 13(2): 97-101.

12. Froughreyhani M., et al., Treatment of Strip Perforation Using Root MTA: A Case Report. Iran Endod J, 2013; 8(2): 80-83.

13. Ariani NGA., Hadriyant W., Perawatan Ulang Saluran Akar Insisivus Lateralis Kiri Maksila dengan Medikamen Kalsium Hidroksida-Chlorhexidine. Maj Ked Gi. Juni. 2013; 20(1): 52-57.

14. Ardana E dan Trilaksana AC. Pasak estetik dari bahan fiber reinforced composite. Dentofasial, 2013; 12(1): 54-59.

15. Subroto, et al., Pasak Customized Fiber Reinforced Composite Indirect pada Gigi Incisivus Lateralis Kiri Atas dengan Dinding Saluran Akar yang Tipis. Maj Ked Gi Ind. 2015; 1(1): 109 - 114. ISSN 2460-0164. 